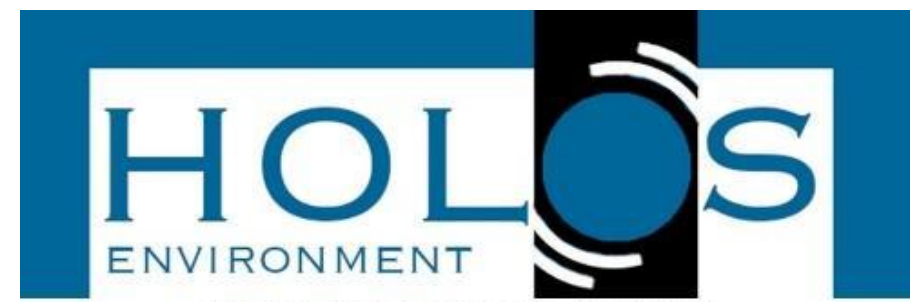

\title{
UMA REVISÃO DE LITERATURA SOBRE O ÍNDICE DE VEGETAÇÃO POR DIFERENÇA NORMALIZADA (NDVI) NO MONITORAMENTO DE ÁREAS DEGRADADAS POR EMPREENDIMENTOS MINERÁRIOS
}

\section{A LITERATURE REVIEW ABOUT THE NORMALIZED DIFFERENCE VEGETATION INDEX (NDVI) IN THE MONITORING OF DEGRADED AREAS BY MINING PROJECTS}

\author{
Luís Alberto Silva ${ }^{1}$
}

Artigo recebido em: 07/02/2020 e aceito para publicação em: 20/02/2020.

DOI: http://dx.doi.org/10.14295/holos.v20i2.12375

\begin{abstract}
Resumo: O sensoriamento remoto - SR é uma técnica empregada no estudo de processos sobre a superfície terrestre a partir do uso de sensores. Uma das suas principais aplicações é no estudo da cobertura vegetal, por meio da aplicação do NDVI, auxiliando, assim, no monitoramento ambiental, por meio do estudo da distribuição espacial da vegetação e das suas prováveis transformações em momentos distintos. O objetivo desse estudo foi apresentar trabalhos que empregaram o NDVI como um elemento de monitoramento ambiental em empreendimentos minerários. Para tal, realizou-se uma revisão bibliográfica, levando-se em conta trabalhos publicados entre 2010 e 2018, empregando os seguintes descritores: "NDVI", "NDVI e monitoramento ambiental", "NDVI e a recuperação de áreas degradadas por mineração", "NDVI e a sua influência na mineração". Em todos os trabalhos concluiu-se a importância do emprego do NDVI, uma vez que o índice forneceu dados significativos sobre o comportamento da cobertura vegetal nos processos minerários, contribuindo, assim no planejamento e gestão territorial das áreas estudadas.
\end{abstract}

Palavras-chave: Sensoriamento Remoto. NDVI. Mineração. Monitoramento Ambiental.

\begin{abstract}
Remote sensing - SR is a technique used in the study of processes on the earth's surface using sensors. One of its main applications is in the study of vegetation cover, with NDVI, thus assisting in environmental monitoring, through the education of the spatial distribution of vegetation and its probable transformations at different times. The aim of this study was to present works that used NDVI as an element of environmental monitoring in mining projects. A bibliographic review was carried out, taking into account works published between 2010 and 2018 using the following descriptors: "NDVI," "NDVI and environmental monitoring," "NDVI and the recovery of areas degraded by mining," "NDVI and its influence on mining." In all works, the importance of using NDVI was concluded, since the index provided essential data on the behavior of vegetation cover in mining processes, thus contributing to the planning and territorial management of the studied areas.
\end{abstract}

Keywords: Remote Sensing. NDVI. Mining. Environmental Monitoring.

\footnotetext{
${ }^{1}$ Universidade Federal de Catalão (UFCAT), Catalão, GO. E-mail: (luis alberto803@hotmail.com)
} 


\section{INTRODUÇÃO}

A exploração mineral é uma das ocupações que mais colabora para a qualidade de vida da sociedade atual, sendo declarado um dos aspectos substanciais para o progresso socioeconômico de muitas nações, sobretudo o Brasil (CARVALHO, 2011). Em razão da necessidade de intervenção antrópica e mudança nos aspectos ambientais da localidade, o empreendimento minerário, culmina na ocorrência de áreas degradadas durante e ao final da exploração (MOURA, 2015).

Conforme mencionam Gonçalves e Mendonça (2012) por tratar-se de um empreendimento degradador, existe uma interpretação preconceituosa sobre tal prática, pois a atividade está ligada ao retardamento, ilegitimidade e depredação ambiental. Lima et al., (2017) corroboram dizendo que a atividade minerária é uma das principais degradadoras em relação aos aspectos ambientais, caso não haja uma perspectiva preservacionista dos responsáveis.

Sendo assim, com o propósito de monitorar essa atividade, surge o sensoriamento remoto. Trata-se de uma ferramenta que permite a obtenção de imagens e outros tipos de informações, oriundos da superfície terrestre, por meio da captação e do registro da energia refletida ou emitida pela superfície (FLORENZANO, 2007). Através do progresso tecnológico proveniente dos sensores remotos, por meio de imagens de satélites, podese avaliar a distribuição espacial da cobertura vegetal, além de possíveis alterações em tempos distintos, assegurando a supervisão do ambiente (NASCIMENTO; LIMA; LIMA, 2014).

Nesse intuito, o Índice de Vegetação por Diferença Normalizada (NDVI) tem sido amplamente empregado em pesquisas voltadas à dinâmica da cobertura vegetal, pois sabendo-se que a degradação ambiental é um dos fatores mais debatidos atualmente, o estudo da dinâmica da cobertura vegetal é de fundamental significância frente as consequências socioambientais que poderão ser geradas (RAMOS, 2016; RIBEIRO et al., 2016; SANTOS; OLIVEIRA, 2015).

A justificativa pelo uso do NDVI se dá em razão da disponibilidade de informações de forma gratuita e acessíveis em meio digital. Ainda além, soma-se o fato de que tais dados, normalmente, correspondem a toda a área de estudo, ou seja, não há a necessidade de generalização de informações (LINHEIRA, 2016).

Cardozo, Pimenta e Ribeiro (2016) mencionam ainda que embora esta tecnologia esteja disponível a muitos anos, poucos estudos ainda empregam o sensoriamento 
remoto no monitoramento das atividades de mineração. Neste sentido, o presente trabalho apresenta o Estado da Arte de generalidades acerca das temáticas de degradação ambiental e recuperação de áreas degradadas, com ênfase no emprego do sensoriamento remoto, mais especificamente o Índice NDVI, como elemento de monitoramento ambiental em empreendimentos minerários.

\section{REVISÃO BIBLIOGRÁFICA}

\subsection{Degradação Ambiental}

Existem na literatura diversas definições de degradação ambiental (MENEGUZZO; CHAICOUSKI, 2010).

Os indivíduos, por meio de um processo de organização para estabelecer-se em um local específico e aprimorar seu desenvolvimento de acordo com o progresso do ser humano, causam diversas transformações no meio, modificando o que denominamos de natural, gerando grande parte das vezes, graves distúrbios ambientais, fazendo com que esse local em específico se torne uma região de risco de vida para o próprio sujeito, causador de toda essa transformação denominada de degradação ambiental (RUBIRA, 2016).

O conceito acima é semelhante ao de Cruz et al., (2008) e fala que a degradação ambiental é oriunda das ações entre componentes socioeconômicos, institucionais e tecnológicos, sendo que elementos como o aumento econômico e populacional, índices de pobreza, urbanização, agricultura, emprego de transportes e energia, acarretam em problemas ambientais, ou seja, a degradação ambiental é consequência de elementos sociais, econômicos e ambientais de uma localidade.

No que diz respeito às definições elucidadas, percebe-se que o termo degradação ambiental é empregado geralmente para fazer alusão às interferências resultantes da ação humana no ambiente. Porém, um fator de destaque que deve ser compartilhado é que a degradação ambiental não é ocasionada apenas pelo homem (MENEGUZZO, 2006).

Ideia essa reforçada por Louzada (2013), que diz que a degradação ambiental vinculada ao antropocentrismo é mais alarmante, porém, pode ser ocasionada por processos e fenômenos naturais. Meneguzzo (2006) cita que as modificações ocasionadas em bacias hidrográficas, por exemplo, podem estar vinculadas às 
circunstâncias naturais. Cunha e Suarte (2017) mencionam que a degradação ambiental pode ser oriunda de ventos que provocam erosão e precipitações que carregam substâncias por meio da lixiviação.

As definições de degradação ambiental e impacto ambiental, tem sido utilizadas como sinônimos, porém, não apresentam o mesmo conceito (RUBIRA, 2016). O impacto ambiental embora tenha sido usado para fazer alusão às características negativas oriundas da ação humana, pode referir-se também aos aspectos positivos (MENEGUZZO; CHAICOUSKI, 2010).

De acordo com Sanchez (2013) a degradação ambiental é definida como qualquer modificação contrária aos processos, atribuições e elementos ambientais, ou como uma modificação contrária à qualidade ambiental. Em outras palavras, equivale à um impacto ambiental negativo. E, por essa razão, Rabelo (2017) explica que a degradação ambiental está vinculada somente às ocorrências negativas que afetam 0 meio ambiente, não tendo nenhum caráter positivo atrelado à sua concepção.

Com relação à degradação oriunda da atividade mineradora, destaca-se os problemas de ordem natural, cultural e social (MATTA, 2006). Para Barreto (2001), os de ordem natural são: alteração de lençol de água subterrânea, poluição sonora, visual, da água, ar e solo, impactos sobre a fauna e a flora, assoreamento, erosão, mobilização da terra, instabilidade de taludes, encostas e terrenos em geral, lançamentos de fragmentos e vibrações.

Bastos (2009) diz que os problemas oriundos da mineração, no Brasil, são diversos, porém os mais evidentes são a poluição das águas, do ar, sonora e a supressão da vegetação, sendo este último o enfoque do trabalho. Conforme menciona Matta (2006) a remoção da vegetação local para abertura das frentes de lavra é uma das etapas principais presentes em quase todos os empreendimentos minerários, sendo que, normalmente, essa ação ocorre por meio do destocamento das árvores.

\subsection{Recuperação de Áreas Degradadas}

De acordo com a Tavares et al., (2008) a definição de área degradada pode ter diversas modificações ao levar em consideração a temática em questão.

Com isso, em razão das inúmeras definições dessa expressão, a norma responsável sobre a criação de projetos de reabilitação de áreas degradadas pela mineração, a NBR 13030 (1999), conceitua área degradada como "aquela com diversos 
graus de alteração dos fatores bióticos e abióticos, causados pelas atividades de mineração".

O termo recuperação vem sendo relacionado diretamente com as áreas degradadas, sobretudo em áreas afetadas por empreendimentos minerários (TATSCH, 2011). Porém, essa palavra tem sido usada com o mesmo sentido de restauração, o que é errôneo, pois as duas palavras têm significados completamente diferentes (LOPES, 2016).

Nesse sentido, Brum (2000) menciona que a recuperação por locais degradados por empreendimentos minerários, pode ser conceituada como uma série de atividades necessárias para que a área em questão retorne ao estado de equilíbrio ambiental, de modo a estar adequada para algum emprego futuro. Isso será possível se, e somente se, a área expor requisitos de estabilidade física, química e geológica.

Já o termo restauração é usado quando há o intuito de retorno da área ao seu estado primitivo, com as mesmas condições da época passada às intervenções (PADILHA, 2016).

\subsection{Sensoriamento Remoto no Estudo da Vegetação}

O intuito do ser humano em aprimorar táticas que assegurem-lhe obter conhecimento e supervisionar os recursos da superfície terrestre por meio de sensores é o que prioriza a temática estudada pelo sensoriamento remoto (ABREU; COUTINHO, 2014). Por esse motivo, Holanda e Guerra (2010) ressaltam que o sensoriamento remoto apresenta-se como um recurso de alta serventia para o estudo da vegetação dentre as quais simplifica a supervisão, a previsão de biomassa, bem como estudos fisiológicos e fenológicos da planta.

O fundamento principal dos estudos em vegetação relacionando o emprego da metodologia de sensoriamento remoto, embasa-se no entendimento da "aparência" que dada vegetação apresenta em um produto característico de sensoriamento remoto, a qual é oriundo de um procedimento que lida com parâmetros e elementos ambientais (PONZONI, 2002).

A vegetação relaciona-se com a radiação solar de forma distinta em relação aos outros elementos naturais (CASARI, 2016). O comportamento espectral da vegetação comporta-se de maneira distinta entre as folhas independentes e o dossel. A figura 1 mostra o comportamento espectral da vegetação nas faixas do espectro magnético. 
Figura 1 - Reflectância espectral característica da folha vegetal verde sadia, no intervalo de onda entre 0,4 e $2,6 \mu \mathrm{m}$

Características Espectrais da Vegetaçắo Verde Sadia

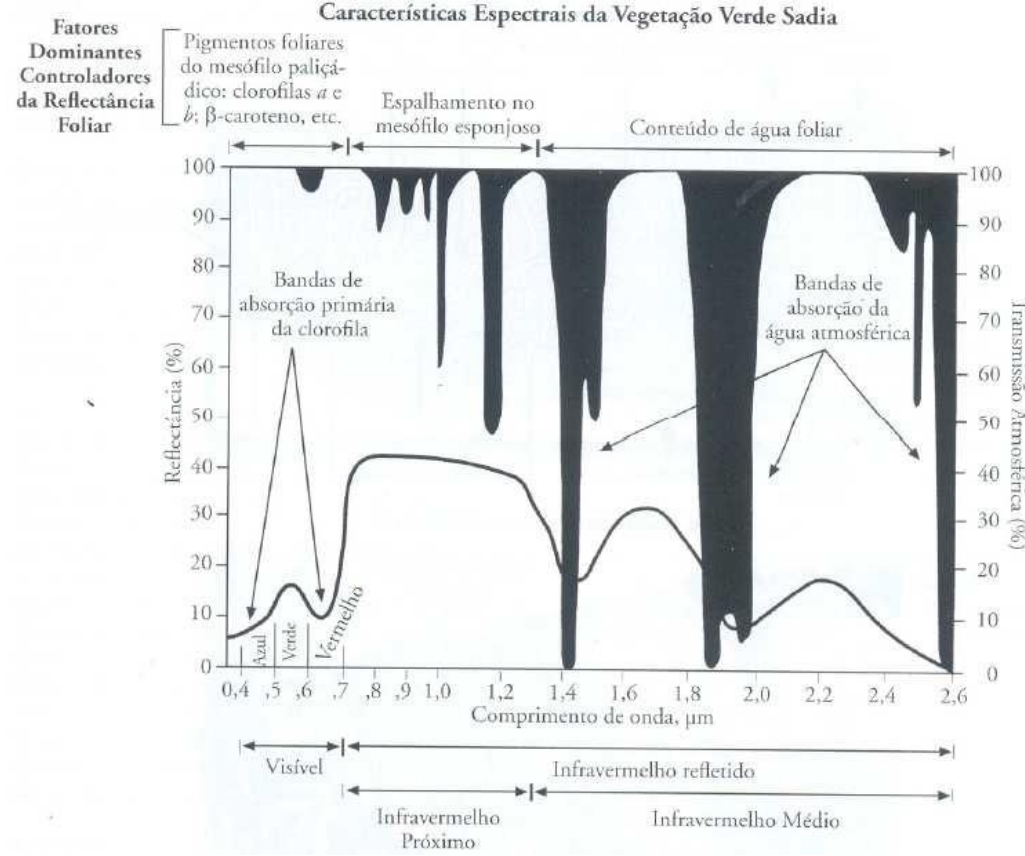

Fonte: JENSEN (2009, p. 359)

Observa-se que, nessa interação há duas bandas de absorção distintas, sendo uma delas próxima a $0,48 \mu \mathrm{m}$ devido à presença de carotenos e a outra próxima a 0,68 $\mu \mathrm{m}$, devido à fotossíntese. Entre estes dois valores há um pico de reflectância em torno de $0,5 \mu \mathrm{m}$, correspondente à cor verde do espectro visível, o que explica a coloração verde das plantas (FIGUEIREDO, 2005).

As respostas espectrais da reflectância da vegetação nas bandas do infravermelho próximo e vermelho permitem que sejam empregados índices de vegetação em inúmeros estudos, assegurando um melhor dinamismo da mesma (NERY et al., 2014).

Além disso, com o progresso tecnológico adquirido pelos sensores remotos, por meio de imagens de satélites, tornou-se viável uma análise da distribuição espacial da vegetação, através de suas transformações temporais, permitindo a supervisão do ambiente. Com isso, os índices de vegetação têm sido amplamente empregados na definição e estimativa do índice de área foliar, biomassa e radiação fotossintética ativa (SILVA et al., 2016).

Existem algumas técnicas usadas para assinalar e estabelecer as transformações estruturais, fisionômicas e dinâmicas da vegetação em datas distintas, destaque para 0 Índice de Vegetação por Diferença Normalizada (NDVI) (AQUINO; OLIVEIRA, 2012). 
Lopes et al., (2010) mencionam que o NDVI é um método simples e com elevada sensibilidade na avaliação da densidade da cobertura vegetal, assegurando a supervisão da vegetação, sendo portanto, um apontador biofísico primordial aos estudos de avaliação e supervisão sazonal e interanual da degradação do ambiente.

\section{METODOLOGIA}

No que diz respeito ao objeto de estudo, a pesquisa caracterizou-se por ser exploratória. Segundo Ramalho e Marques (2010, p. 6): "o planejamento do tipo de pesquisa exploratória está relacionado à pesquisa bibliográfica sobre um tema estudado".

$\mathrm{Na}$ coleta de dados, empregou-se pesquisa bibliográfica realizada através de revisão e estudo em banco de dados sobre o assunto em questão para a melhor conceituação do tema da pesquisa. Com esse intuito, a fundamentação teórica tem como objetivo "colocar o pesquisador em contato direto com tudo que foi escrito, dito ou filmado sobre determinado assunto" (LAKATOS; MARCONI, 2010, p.166).

A pesquisa bibliográfica foi realizada empregando-se os seguintes descritores: "NDVI", "NDVI e monitoramento ambiental", "NDVI e a recuperação de áreas degradadas por mineração", "NDVI e a sua influência na mineração". Os critérios de inclusão para os estudos encontrados foram: disponibilidade do material na íntegra, publicações em português e inglês apenas, a abordagem do índice NDVI no monitoramento ambiental, sobretudo de empreendimentos minerários e materiais publicados entre 2010 e 2018. Foram excluídos estudos que relatavam o emprego desse mesmo índice porém para atividades que não considerassem a mineração em seu escopo, materiais produzidos fora do tempo determinado, arquivos que não foram disponibilizados na íntegra e trabalhos em outros idiomas senão o português e inglês.

\section{RESULTADOS E DISCUSSÕES}

Erener (2011) realizou um monitoramento da cobertura vegetal de uma mineradora de carvão da Turquia, empregando o sensoriamento remoto, sobretudo os índices Simple Ratio (SR), Redified Simple Ratio (RSR), Tasseled Cap Transformation e NDVI. O resultado das análises evidenciou um progresso variando entre moderado a bom na recuperação da área. Além disso, os dados detectados remotamente serviram 
de informação no monitoramento do progresso da reabilitação de grandes localidades estendidas.

Li et al., (2012) em seu estudo objetivaram monitorar, por meio do NDVI, o curso dinâmico da mudança da cobertura vegetal numa mineradora situada na China. Os resultados mostraram que a cobertura vegetal na área total de mineração atingiu o seu nível mais alto nos últimos 20 anos. Ainda além, concluiu-se que a técnica utilizada pode ser empregada na avaliação e gestão ambiental de áreas minerárias, uma vez que permite monitorar e analisar a cobertura vegetal e suas mudanças rápidas de forma quantitativa.

Koruyan et al., (2012) estudaram o aumento regional de pedreiras de mármore e a vegetação acometida por tal atividade no decorrer de uma década na Turquia, empregando, para tal, o NDVI. Os resultados trouxeram uma alteração na vegetação natural em razão do aumento do nível de produção da pedreira de mármore, confirmando, assim, um aumento na atividade de mineração na região.

Um estudo feito por Silva (2013) teve como intuito a caracterização ambiental em três regiões minerárias de saibro empregando-se geotecnologias. A pesquisa contribuiu para a análise e quantificação de alguns elementos ambientais nos locais de extração estudados, bem como na caracterização dinâmica desses aspectos entre os anos de 2004 e 2009.

Huang et al., (2015) em seu estudo para esclarecerem a relação entre mineração de carvão e danos à vegetação local, criaram imagens de sensoriamento remoto de alta resolução espaço-temporal, utilizando-se o NDVI. Dados mostrando a superfície da mina de carvão e a variação da vegetação na mina de carvão de Xinzhouyao permitiram identificar fatores influentes. Os valores quantificados do efeito sintético do NDVI da mineração de carvão e mudanças no clima local foram então avaliados.

A pesquisa realizada por Silva e Pinto (2014) comparou a similaridade entre os métodos de análise de componentes principais e do NDVI para análise multitemporal de vegetação. Os resultados asseguram que desde o início da instalação da exploração, que ocorreu no ano de 1990, não houve supressão significativa da vegetação do entorno.

Li et al., (2015) em seu estudo avaliaram, por meio do NDVI, o processo de degradação e recuperação de áreas degradas em minas de carvão numa região americana no decorrer de quase trinta décadas. Os resultados do estudo evidenciaram que a análise das trajetórias de NDVI em escala de pixels pode reconstruir os agravantes resultantes da mineração e evidenciar o histórico de recuperação de áreas degradas e, 
portanto, constituiu-se como base científica para o gerenciamento de recuperação de áreas degradadas.

Rocha e Santos (2015) em seu estudo apresentaram dados georreferenciados do município de Picuí, espacializando um escopo da vegetação no município através de uma análise multi-temporal. Concluíram que há processos erosivos em vários pontos do município em razão de algumas atividades do processo, sobretudo a mineração.

Cardozo, Pimenta e Ribeiro (2016) utilizaram o sensoriamento remoto com o intuito de analisar o impacto ambiental e o progresso nas mudanças na vegetação em uma área de mineração abandonada. Os resultados do estudo evidenciaram a possibilidade de mensurar a transformação em cada região da paisagem, detectando o desenvolvimento das mudanças na vegetação natural, por meio de uma análise temporal das imagens entre 1985 e 2011.

Kalabin, Gorny e Kritsuk (2016) comprovaram em sua pesquisa, por meio do NDVI, a significância dos dados do espaço digital que foram empregados na estimativa quantitativa operacional regional e local da natureza na área de mineração e processamento mineral de uma empresa russa. Os dados da análise mostraram o risco ambiental tolerável, comprovado pelo NDVI relativamente alto e perda de vegetação permitida (17\%) durante o período de mineração e processamento na área de monitoramento.

Sari e Rosalinda (2016) em seu trabalho discutiram sobre o mapeamento e monitoramento da densidade de manguezais na área de mineração de estanho, utilizando-se, para tal, o índice NDVI. O resultado mostrou que a atividade de mineração de estanho na área costeira do sul de Bangka acarretou na diminuição da densidade de manguezais.

Boengiu, lonuş e Marinescu (2016) estudaram as alterações acarretadas oriundas da atividade minerária, empregando para tal, medições de campo, imagens de satélite Landsat e índice NDVI. A pesquisa revelou que a exploração de lignito implicou em deslocamento, realocação e armazenamento de materiais, o que levou a uma alteração significativa no cenário geomorfológico da região, acarretando na construção de algumas estruturas antrópicas, como cavidades e formas de relevo proeminentes.

Lima et al., (2017) desenvolveram um estudo, de forma temporal, para análise das mudanças na vegetação em um garimpo diamantífero, entre 2001 e 2016, empregando índices de vegetação distintos. O resultado do estudo evidenciou que o emprego de sensores orbitais auxiliaram nos estudos de impactos ambientais e na caracterização da 
região em recuperação, de forma a supervisionar e quantificar características ambientais afetadas pela atividade mineradora.

Santos et al., (2017) tiveram como objetivo analisar a vegetação presente na área da microbacia do rio Corrente, através do NDVI. O local em questão está situado no município de Pedro II, conhecido pela mineração de opalas. Com base nos resultados obtidos, percebeu-se que a mineração têm causado pouco impacto ambiental, no que tange à supressão da vegetação, uma vez que as minas são de pequeno porte, acarretando dessa forma, um impacto pontual que não se expande ao longo da bacia.

Kuhnen et al., (2017) em sua pesquisa, avaliaram análises de séries temporais em imagens do satélite Landsat 7, sensor $\mathrm{ETM}_{+}$, para derivar índices de cobertura vegetal na Bacia Carbonífera, com o intuito de verificar o impacto na cobertura da terra ou nas alterações decorrentes da atividade minerária. O estudo concluiu uma grande tendência na degradação ambiental sobretudo em razão do empreendimento minerário.

Gómez-Rodriguez et al., (2017) em seu trabalho investigaram o progresso das alterações da cobertura do solo produzidas pela atividade minerária de ouro no período de 24 anos. A pesquisa concluiu que aproximadamente $124,8 \mathrm{~km}^{2}$ de bosque foram perdidos no período analisado. Porém, em relação aos corpos de água, evidenciou-se que estes ganharam uma área de $66,3 \mathrm{~km}^{2}$.

Yang et al., (2018) descreveram em sua pesquisa um método automatizado para identificar áreas degradadas pela mineração, numa região norte-americana, bem como a caracterização da recuperação da cobertura vegetal e a progressão ao longo do tempo da mesma, utilizando-se para isso o NDVI.

Santos et al., (2018) investigaram, empregando-se o NDVI, o processo de ocupação do município de Parauapebas, conhecido por seu potencial mineral e florestal. O resultado evidenciou que as áreas protegidas pela legislação, bem como aquelas atreladas à atividade minerária sofreram uma supressão da vegetação inferior às demais áreas.

Yang et al., (2018) objetivaram em seu estudo avaliar a capacidade do algoritmo LandTrendr e das imagens Landsat na detecção de mudança da vegetação e caracterização da dinâmica histórica numa área de mineração de carvão na Austrália. Os resultados mostraram que mais de 2982ha das 4573ha de terra que foram degradadas já encontram-se cobertas por vegetação. Logo, esse empreendimento minerário cumpriu a legislação de mineração, angariando esforços progressivos de reabilitação e estabelecimento de vegetação. 
O emprego de geotecnologias ajuda na análise e mensuração do progresso e transformação da paisagem, gerando dados válidos (BOOTH; FRANCELINO, 2016). Além disso, seu uso tem sido amplamente difundido, uma vez que auxilia significativamente na tomada de decisões, devido à rapidez, eficácia e precisão nas análises voltadas às áreas degradadas (ROSENDO, 2005).

Saito (2011) menciona que através dos SIG's tornou-se possível analisar locais em datas distintas, reproduzir situações futuras, verificar ambientes por multicritérios e manusear dados. Percebe-se então que dentro do universo que engloba as geotecnologias, o sensoriamento remoto possibilita uma análise das modificações ou alterações verificadas na superfície no decorrer dos anos (JESUS, 2010).

Prakash e Gupta (1998) afirmam que as mudanças no uso da terra estão invariavelmente associadas à mineração de recursos naturais. O estudo de mudanças no padrão de uso da terra usando dados detectados remotamente é baseado na comparação de dados sequenciais no tempo. Petja, Twumasi e Tengbeh (2006) afirmam que o método de diferenciação de imagem (NDVI) é utilizado para avaliar a condição da vegetação na área de estudo em questão.

\section{CONCLUSÃO}

Conforme observado nos estudos apresentados, os SIG's e o sensoriamento remoto possuem uma função de destaque nos empreendimentos minerários, pois quando empregados concomitantemente, apresentam dados que possibilitam uma avaliação prévia à operação de um empreendimento mineiro, no decorrer da atividade e após o fechamento de mina, sobretudo no que tange à recuperação ambiental para reintegração da área ao sistema produtivo.

Ainda além, o sensoriamento remoto permitiu análises eficientes, tornando-o uma ferramenta imprescindível no entendimento de diversos elementos e suas interações. Destaca-se ainda que as geotecnologias constituem-se como aliadas no planejamento, monitoramento e fiscalização ambiental, com o intuito de proteger o meio ambiente.

\section{REFERÊNCIAS}

ABREU, K. M. P.; COUTINHO, L. M. Sensoriamento remoto aplicado ao estudo da vegetação com ênfase em índice de vegetação e métricas da paisagem. Vértices, Campos dos Goytacazes/RJ, v.16, n.1, p. 173-198,2014. ttps://doi.org/10.5935/1809-2667.20140012 
ASSOCIAÇÃO BRASILEIRA DE NORMAS TÉCNICAS. NBR 13030: Elaboração e apresentação de projeto de reabilitação de áreas degradadas pela mineração. Rio de Janeiro, 1999.

AQUINO, C. M. S.; OLIVEIRA, J. G. B. Estudo da dinâmica do índice de vegetacão por diferença normalizada (NDVI) no núcleo de São Raimundo Nonato-PI. GEOUSP - Espaço e Tempo, n. 31, p. 157-168, 2012.

BARRETO, M. L. Mineração e desenvolvimento sustentável: desafios para o Brasil. Rio de Janeiro: CETEM/MCT, 2001. 215 p.

BASTOS, B. R. N. P. Efeitos degradativos ao meio ambiente causados pela atividade garimpeira no município de Juína-MT. 2009. 43 p. Trabalho de Conclusão de Curso (Licenciatura em Geografia) - Instituto Superior de Educação do Vale do Juruena, Juina, 2009.

BOENGIU, S,; IONUŞ, O.; MARINESCU, E. Man-made changes of the relief due to the mining activities within Husnicioara open pit (Mehedinţi County, Romania). Procedia Environmental Sciences, v. 32, p. 256-263, 2016. https://doi.org/10.1016/j.proenv.2016.03.030

BOOTH, M. C.; FRANCELINO, M. R. Geotecnologias aplicadas à análise espaço temporal do uso e cobertura de áreas degradadas por mineração em recuperação na Flona Jamari, Rondônia. In: XI FÓRUM DA PÓS-GRADUAÇÃO DA UFRRJ, 11., 2016, Seropédica. [Anais...]. Seropédica: Fórum da Pós-Graduação da UFRRJ, 2016. p. 1.

BRUM, I. A. S. Recuperação de áreas degradadas pela mineração. 2000. 22 p. Trabalho de conclusão de curso (Especialização em Gerenciamento e Tecnologias Ambientais na Indústria) - Universidade Federal da Bahia, Salvador, 2000.

CARDOZO, F. A. C.; PIMENTA, M. M.; RIBEIRO, R. R. Sensoriamento remoto aplicado na detecção de áreas degradadas pela mineração no sul do Brasil entre 1985 - 2011. Tecnológica, Santa Cruz do Sul, v. 20, n. 2, p. 97-102, 2016.

https://doi.org/10.17058/tecnolog.v20i2.7369

CARVALHO, R. P. B. Contribuições da análise de geosssistemas na recuperação de áreas degradadas por mineração. Caderno de Geografia, v.21, n.36, p. 13-28, 2011. DOI:

CASARI, R. A. C. N. Desenvolvimento de uma plataforma estabilizadora para aeronaves remotamente pilotadas visando a obtenção de índices de vegetação e sensoriamento remoto. 2016. 103 p. Trabalho de Conclusão de Curso (Bacharelado em Engenharia de Energia) - Universidade de Brasília, Brasília, 2016.

CRUZ, C. E. B.; LIMA, J. S.; BRITO, A. V. C.; FARIAS, R. M. O.; LIMA, P. V. P. S. Fatores de degradação ambiental nos agropolos do Ceará. In: CONGRESSO DA SOCIEDADE BRASILEIRA DE ECONOMIA, ADMINISTRAÇÃO E SOCIOLOGIA RURAL, 46., 2008, Rio Branco. [Anais...]. Rio Branco: SOBER, 2008. p.1-18.

CUNHA, E. L.; SUARTE, J. S. M. Impacto ambiental: uma perspectiva dos conceitos relacionados à efetividade dos princípios usados pelo EIA-RIMA. Revista Científica do Norte Goiano, v. 4, n. 1, p.74-87, 2017.

ERENER, A. Remote sensing of vegetation health for reclaimed areas of Seyitömer open cast coal mine. International Journal of Coal Geology, v. 86, n. 1, p. 20-26, 2011.

https://doi.org/10.1016/i.coal.2010.12.009

FIGUEIREDO, D. Conceitos básicos de sensoriamento remoto. Conab, 2005. 
FLORENZANO, T. G. Iniciação em sensoriamento remoto. 2.ed. de imagens de satélite para estudos ambientais. São Paulo: Oficina de Textos, 2007.

GÓMEZ-RODRIGUEZ, M. E.; MOLINA-PÉREZ, F. J.; AGUDELO-ECHAVARRÍA, D. M.; CAÑÓN-BARRIGA, J. E.; VÉLEZ-MACÍAS, F. J. Mudanças na cobertura do solo no município de Nechí: Uma aproximação ao impacto ambiental da mineração, 1986-2010. Revista Facultad de Ingeniería (Rev. Fac. Ing.), v. 26, n. 45, p. 149-163, 2017. https://doi.org/10.19053/01211129.v26.n45.2017.6423

GONÇALVES, R. J. A. F.; MENDONÇA, M. R. Trabalho e garimpo: atividade garimpeira de diamantes na comunidade de douradinho no município de Coromandel/MG. Espaço em Revista, v. 14, n. 1, p. 86-95, 2012.

HOLANDA, A. S.; GUERRA, C. E. Monitoramento da região do Eixo- Forte no município de Santarém - PA utilizando imagens dos índices de vegetação de NDVI e NDWI. In: SIMPÓSIO BRASILEIRO DE CIÊNCIAS GEODÉSICAS E TECNOLOGIAS DA GEOINFORMAÇÃO, 3., Recife. Anais [...]. Recife: UFOPA, 2010. p.001-005.

HUANG, Y.; TIAN, F.; WANG, Y.; WANG, M.; HU, Z. Effect of coal mining on vegetation disturbance and associated carbon loss. Environmental Earth Sciences, v. 73, n. 5, p. 23292342, 2015. https://doi.org/10.1007/s12665-014-3584-z

JENSEN, J. R. Sensoriamento remoto do ambiente: uma perspectiva em recursos terrestres. Tradução José Carlos Neves Epiphanio (coord.) [et al]. São José dos Campos: Parêntese, 2009. 598 p.

JESUS, J. R. P. Análise da Dinâmica do Uso e Ocupação do Solo no Município de São Gonçalo do Rio Abaixo/MG - 1988 a 2009. 2010. 37 p. Trabalho de Conclusão de Curso (Especialização em Geoprocessamento) - Universidade Federal de Minas Gerais, Belo Horizonte, 2010.

KALABIN, G. V.; GORNY, V. I.; KRITSUK, S. G. Environmental appraisal of the area of Kachkanar mining-and-processing plant by satellite monitoring data. Journal of Mining Science, v. 52, n. 2, p. 394-400, 2016. https://doi.org/10.1134/S1062739116020562

KORUYAN, K.; DELIORMANLI, A. H.; KARAKA, Z.; MOMAYEZ, M.; LU, H.; YALÇIN, E. Remote sensing in management of mining land and proximate habitat. Journal of the

Southern African Institute of Mining and Metallurgy, v. 112, n. 7, p. 667-672, 2012.

KUHNEN, B. D. S.; BORTOLATO, C. V.; VIEIRA, C. A. O.; CARDOZO, G. S.; MONDINI, L.; PEDROSO, V. L. Análises de séries temporais em imagens do satélite Landsat para verificação do impacto na cobertura da terra, ocasionadas pelas atividades de mineração na região carbonífera do estado de Santa Catarina. In: CONGRESSO BRASILEIRO DE CARTOGRAFIA E EXPOSICARTA, 27., Rio de Janeiro. [Anais...]. Rio de Janeiro: Sociedade Brasileira de Cartografia, Geodésia, Fotogrametria e Sensoriamento Remoto, 2017. p. 596-600.

LAKATOS, E. M.; MARCONI, M. A. Metodologia do trabalho científico. São Paulo: Atlas, 2010.

LI, L. C.; DENG, L.; CAO, Y.; XIAO, W. J.; CHEN, C. Y.; LI, H. Z. Vegetation dynamic monitoring in mining area based on NDVI serial images and dimidiate pixel model. Journal of Central South University of Forestry and Technology, v. 32, n. 6, p. 18-23, 2012.

LI, J.; ZIPPER, C.; LI, S.; DONOVAN, P.; WYNNE, R.; OLIPHANT, A.; XIA, Q. Character analysis of mining disturbance and reclamation trajectory in surface coal-mine area by time- 
series NDVI. Transactions of the Chinese Society of Agricultural Engineering, v. 31, n. 16, p. 251-257, 2015. https://doi.org/10.11975/j.issn.1002-6819.2015.16.033.

LIMA, A.; MEDEIRO, F. S. L.; PÓVOAS, H. S. S.; NOGALES, R. V.; TORLAY, R. Modificações na dinâmica da vegetação provocadas por garimpos de diamante na Chapada DiamantinaBahia. In: SIMPÓSIO BRASILEIRO DE SENSORIAMENTO REMOTO, 18., Santos. [Anais...]. Santos: SBSR, 2017. p. 7102-7109.

LINHEIRA, G. Avaliação da ocorrência de seca na Bacia Hidrográfica do Rio do Peixe entre 2001 e 2010 utilizando o Índice de Vegetação por Diferença Normalizada (NDVI). 2016. 96f. Dissertação (Mestrado em Planejamento Territorial e Desenvolvimento Socioambiental) - Universidade do Estado de Santa Catarina, Florianópolis, 2016.

LOPES, H. L.; CANDEIAS, A. L. B.; ACCIOLY, L. J. O.; SOBRAL, M. C. M.; PACHECO, A. P. Parâmetros biofísicos na detecção de mudanças na cobertura e uso do solo em bacias hidrográficas. Revista Brasileira de Engenharia Agrícola e Ambiental, v.14, n.11, p.12101219, 2010. https://doi.org/10.1590/S1415-43662010001100011

LOPES, T. L. Técnicas utilizadas na recuperação ambiental de áreas degradadas pela mineração de calcário no município de Caçapava do Sul - RS. 2016. 87 p. Trabalho de Conclusão de Curso (Bacharelado em Engenharia Ambiental e Sanitária) - Universidade Federal do Pampa, Caçapava do Sul, 2016.

LOUZADA, A. Gestão ambiental, conceitos e definições. 2013. Disponível em: http://www.ebah.com.br/content/ABAAABQDYAJ/gestao-ambiental-conceitos-definicoes. Acesso em: 05 abr. 2018.

MATTA, P. M. O garimpo na Chapada Diamantina e seus impactos ambientais: uma visão histórica e suas perspectivas futuras. 2006. 187 p. Dissertação (Programa de Pós-Graduação em Engenharia Ambiental Urbana) - Universidade Federal da Bahia, Salvador, 2006.

MENEGUZZO, I. S. Análise da degradação ambiental na área urbana da bacia do Arroio Gertrudes, Ponta Grossa, PR: uma contribuição ao planejamento ambiental. 2006. 89 p. Dissertação (Mestrado, Programa de Pós-graduação em Ciência do Solo) - Universidade Federal do Paraná, Curitiba, 2006.

MENEGUZZO, I. S; CHAICOUSKI, A. Reflexões acerca dos conceitos de degradação ambiental, impacto ambiental e conservação da natureza. Revista Geografia, Londrina, v. 9, n. 1, p. 181-185, 2010. http://dx.doi.org/10.5433/2447-1747.2010v19n1p181.

MOURA, J. S. Recuperação de áreas degradadas pela mineração. 2015. 27 p. Trabalho de conclusão de curso (Graduação em Tecnologia em Mineração) - Universidade Estadual de Goiás, Niquelândia, 2015.

NASCIMENTO, S. S.; LIMA, E. R. V.; LIMA, P. P. S. Uso do NDVI na análise temporal da degradação da caatinga na sub-bacia do Alto Paraíba. Revista OKARA: Geografia em debate, v.8, n.1, p. 72-93, 2014.

NERY, C. V. M.; MOREIRA, A. A.; FERNANDES, F. H. S.; ALMEIDA, L. S.; ALMEIDA, R. P. Utilização do modelo linear de mistura espectral e NDVI para avaliação do comportamento de área desmatada no município de Rio Pardo de Minas/MG. Caminhos de Geografia, v. 15, n. 49, p. 104-112, 2014.

PADILHA, R. T. Avaliação da restauração de área de preservação permanente degradada do Córrego Fundo, em Cuiabá - MT. 2016. 30 p. Trabalho de Conclusão de Curso

(Bacharelado em Engenharia Florestal) - Universidade Federal do Mato Grosso, Cuiabá, 2016. 
PETJA, B.; TWUMASI, Y.; TENGBEH, G. The use of remote sensing to detect asbestos mining degradation in Mafefe and Mathabatha, South Africa. In: IEEE International Symposium on Geoscience and Remote Sensing. [Anais...]. IEEE, 2006. p. 1591-1593.

https://doi.org/10.1109/IGARSS.2006.410

PONZONI, F. J. Sensoriamento remoto no estudo da vegetação: diagnosticando a Mata Atlântica. In: RUDORFF, B. F. T. et al. Curso de uso de sensoriamento remoto no estudo do meio ambiente. São José dos Campos: INPE, 2002. cap. 8, p. 1-27.

PRAKASH, A.; GUPTA, R. P. Land-use mapping and change detection in a coal mining area-a case study in the Jharia coalfield, India. International journal of remote sensing, v. 19, n. 3, p. 391-410, 1998. https://doi.org/10.1080/014311698216053

RABELO, D. R. Evidências da degradação ambiental na vertente seca da Serra de Uruburetama, Ceará-Brasil. Revista Geonorte, v. 8, n. 29, p. 72-85, 2017.

https://doi.org/10.21170/geonorte.2017.V.8.N.29.72.85

RAMALHO, A. M. C.; MARQUES, F. L. M. Pesquisa e ensino em geografia. 1. ed. Campina Grande: EDUEPB, 2010.

RAMOS, M. F. Estudo da variação temporal do Índice de Vegetação por Diferença Normalizada em Juiz de Fora a partir de imagens de satélite. 2016. 39f. Trabalho de Conclusão de Curso (Bacharelado em Engenharia Ambiental) - Universidade Federal de Juiz de Fora, Juiz de Fora, 2016.

RIBEIRO, E. P.; NOBREGA, R. S.; MOTA FILHO, F. O.; MOREIRA, E. B. M. Estimativa dos índices de vegetação na detecção de mudanças ambientais na bacia hidrográfica do rio Pajeú. Revista Geosul, v. 31, n. 62, p. 59-92, 2016. https://doi.org/10.5007/2177$\underline{5230.2016 v 31 n 62 p 59}$.

ROCHA, J. G.; SANTOS, M. L. F. Uso de geotecnologias para identificação e espacialização multi-temporal da cobertura vegetal no município de Picuí-PB a partir do uso de imagens TM/LANDSAT e CCD/CBERS. In: ENCONTRO NACIONAL DA ANPEGE, 11., Presidente Prudente. [Anais...]. Presidente Prudente: ENANPEGE, 2015. p.4552-4564.

ROSENDO, J. S. Índices de vegetação e monitoramento do uso do solo e cobertura vegetal na bacia do rio Araguari-MG, utilizando dados do sensor MODIS. 2005. 130 p. Dissertação (Mestrado, Programa de Pós-Graduação em Geografia) - Universidade Federal de Uberlândia, Uberlândia, 2005.

RUBIRA, F. G. Definição e diferenciação dos conceitos de áreas verdes/espaços livres e degradação ambiental/impacto ambiental. Caderno de Geografia, v. 26, n. 45, p. 134-150, 2016. https://doi.org/10.5752/P.2318-2962.2016v26n45p134

SAITO, S. M. Desastres naturais e geotecnologias: vulnerabilidade. São José dos Campos: INPE, 2011. $35 \mathrm{p}$.

SANCHEZ, L. E. Avaliação do impacto ambiental: conceitos e métodos. 2 ed. São Paulo: Oficina de Textos, 2013. 584 p.

SANTOS, F. A.; OLIVEIRA, W. A. S. Aplicação do Índice de Vegetação por Diferença Normalizada (NDVI) para avaliação da cobertura vegetal do entorno do Açude Caldeirão, em Piripiri (PI), Brasil. Revista Equador (UFPI), v. 4, n. 2, p.114-127, 2015. 
SANTOS, A. B. S.; COSTA, G. J. A.; SOUSA, K. R.; SANTOS, M. R. O. Análise do índice de cobertura vegetal na microbacia do Rio Corrente no município de Pedro II - Piauí. In: SIMPÓSIO REGIONAL DE GEOPROCESSAMENTO E SENSORIAMENTO REMOTO, Salvador. [Anais...]. Salvador: IFPI, 2017. p. 657-662.

SANTOS, M. N. S.; ALMEIDA, J. A. C.; ROCHA, J. L. S.; VIDAL, M. R. Uso do NDVI para análise temporal da cobertura vegetal município de Parauapebas - PA. In: ENCONTRO DE PÓS GRADUAÇÃO, 3., Marabá. [Anais...]. Marabá: Unifesspa, 2018. v. 1. p. 22-31.

SARI, S. P.; ROSALINA, D. Mapping and monitoring of mangrove density changes on tin mining area. Procedia Environmental Sciences, v. 33, p. 436-442, 2016.

https://doi.org/10.1016/i.proenv.2016.03.094

SILVA, L. P. S. Diagnóstico ambiental preliminar de áreas de mineração de saibro no município de Macapá-AP, com o suporte de ferramentas de geotecnologias. 2013. 48 p. Trabalho de Conclusão de Curso (Bacharelado em Ciências Ambientais) - Universidade Federal do Amapá, Macapá, 2013.

SILVA, F. S.; PINTO, J. L. C. Comparativo estatístico multitemporal entre ACP e NDVI na detecção de supressão da vegetação em imagens Landsat 5 TM. In: SIMPOSIO MINEIRO DE GEOGRAFIA, 1., Alfenas. [Anais...]. Alfenas: Universidade Federal de Alfenas, 2014. p. 16761686.

SILVA, A. L. C.; AZEVEDO, J. R. G.; KOCH, H.; HATTERMANN, F. F. Análise do índice de vegetação por diferença normalizada (NDVI) na bacia do rio Pajeú, PE. In: SIMPÓSIO DA BACIA HIDROGRÁFICA DO RIO SÃO FRANCISCO, 1., Juazeiro. [Anais...]. Juazeiro: SBHSF, 2016. p. 1-8.

TAVARES, S. R. L.; MELO, A. S.; ANDRADE, A. G.; ROSSI, C. Q.; CAPECHE, C. L.; BALIEIRO, F. C.; DONAGEMMA, G. K.; CHAER, G. M.; POLIDORO, J. C.; MACEDO, J. R.; PRADO, R. B.; FERRAZ, R. P. D.; PIMENTA, T. S. Curso de recuperação de áreas degradadas: a visão da Ciência do Solo no contexto do diagnóstico, manejo, indicadores de monitoramento e estratégias de recuperação. 1 ed. Rio de Janeiro: Embrapa Solos, 2008. 228 p.

TATSCH, G. L. Recuperação de uma área degradada através do método de nucleação Santa Margarida do Sul, RS. 2011. 40 f. Relatório de Estágio (Graduação em Engenharia Florestal) - Universidade Federal do Pampa, São Gabriel, 2011.

YANG, Y.; ERSKINE, P. D.; LECHNER, A. M.; MULLIGAN, D.; ZHANG, S.; WANG, Z. Detecting the dynamics of vegetation disturbance and recovery in surface mining area via Landsat imagery and LandTrendr algorithm. Journal of Cleaner Production, v. 178, p. 353362, 2018. https://doi.org/10.1016/j.jclepro.2018.01.050

YANG, Z.; LI, J.; ZIPPER, Z. E.; SHEN, Y.; MIAO, H.; DONOVAN, P. F. Identification of the disturbance and trajectory types in mining areas using multitemporal remote sensing images. Science of the total environment, v. 644, p. 916-927, 2018.

https://doi.org/10.1016/j.scitotenv.2018.06.341 